Southern Illinois University Carbondale

OpenSIUC

Articles

Department of Plant, Soil, and Agricultural Systems

$11-2013$

\title{
Determining the effect of UV-C, high intensity ultrasound and nonthermal atmospheric plasma treatments on reducing the allergenicity of a-casein and whey proteins
}

Chatrapati V.R.K. Tammineedi

Southern Illinois University Carbondale

Ruplal Choudhary

Southern Illinois University Carbondale, choudhry@siu.edu

Gabriela C. Perez-Alvarado

Southern Illinois University Carbondale

Dennis G. Watson

Southern Illinois University Carbondale, dwatson@siu.edu

Follow this and additional works at: http://opensiuc.lib.siu.edu/psas_articles

(C)2013. This manuscript version is made available under the CC-BY-NC-ND 4.0 license

http://creativecommons.org/licenses/by-nc-nd/4.0/

\section{Recommended Citation}

Tammineedi, Chatrapati V., Choudhary, Ruplal, Perez-Alvarado, Gabriela C. and Watson, Dennis G. "Determining the effect of UV-C, high intensity ultrasound and nonthermal atmospheric plasma treatments on reducing the allergenicity of a-casein and whey proteins." LWT - Food Science and Technology 54, No. 1 (Nov 2013): 35-41. doi:10.1016/j.lwt.2013.05.020.

This Article is brought to you for free and open access by the Department of Plant, Soil, and Agricultural Systems at OpenSIUC. It has been accepted for inclusion in Articles by an authorized administrator of OpenSIUC. For more information, please contact opensiuc@lib.siu.edu. 


\title{
Determining the effect of UV-C, high intensity ultrasound and nonthermal atmospheric plasma treatments on reducing the allergenicity of $\alpha$-casein and whey proteins
}

\author{
Chatrapati V. R. K.Tammineedi ${ }^{\mathrm{a}}$, Ruplal Choudhar $\mathrm{a}^{\mathrm{a} *}$,Gabriela C. Perez-Alvarado ${ }^{\mathrm{b}}$, \\ Dennis G. Watson ${ }^{\mathrm{a}}$
}

${ }^{a}$ Department of Plant, Soil and Agricultural Systems, Southern Illinois University, Carbondale, IL 62901 USA

${ }^{\mathrm{b}}$ Department of Chemistry and Biochemistry, Southern Illinois University, Carbondale, IL 62901 USA

*Corresponding author. Department of Plant, Soil and Agricultural Systems, 1205 Lincoln Drive, Room 176, Mail code 4415, Southern Illinois University, Carbondale, IL 62901, USA. Phone: 618453 6985, FAX: 618453 7457, Email: choudhry@ siu.edu.

\begin{abstract}
:
Casein, $\beta$-lactoglobulin and $\alpha$-lactalbumin are major milk protein allergens. The objective of this study was to investigate the effect of high intensity ultrasound, nonthermal atmospheric plasma and UV-C light treatments in reducing the allergenicity of isolated major milk proteins. SDSPAGE results for ultrasound and plasma treatments showed no noticeable change in gel band intensities for $\alpha$-casein, $\beta$-lactoglobulin and $\alpha$-lactalbumin, indicating no change in protein concentration. Ci-ELISA analysis showed that there was no significant difference $(p>0.05)$ in $\mathrm{IgE}$ binding values for control and treated samples in ultrasound and plasma treatment conditions tested in this study. UV-C treatment for 15 min resulted in reduced intensities of all three protein bands in SDS-PAGE gel. Ci-ELISA of UV-C treated samples showed, significant reduction ( $p<$ 0.05 ) in IgE binding values compared to control samples indicating reduction in allergenicity of proteins (25\% reduction for $\alpha$-casein and $27.7 \%$ reduction for whey fractions). Further investigations using in vivo clinical trials need to be conducted to confirm this result.
\end{abstract}

Key words: UV-C light, High intensity Ultrasound, Nonthermal atmospheric plasma, Milk, Allergen, IgE binding.

Abbreviations: UV-C $=$ Ultraviolet-C, SDS-PAGE $=$ Sodium dodecyl sulfate polyacrylamide gel electrophoresis, Ci-ELISA = Competitive indirect enzyme-linked immunosorbent assay, PBS $=$ Phosphate buffered saline, PBST $=$ Phosphate buffered saline with Tween 20, NTAP $=$ Nonthermal atmospheric plasma, PUV $=$ Pulsed UV light.

(C) 2013. This manuscript version is made available under the CC-BY-NC-ND 4.0 license http://creativecommons.org/licenses/by-nc-nd/4.0/

The published article is available at: $\underline{\text { http://dx.doi.org/10.1016/j.lwt.2013.05.020 }}$ 


\subsection{Introduction}

Milk is one of twelve allergenic ingredients whose presence has to be declared as per the directive 2003/89/EC (Monaci et al., 2006). Milk allergy is the most common food allergy in the children under the age of two years. About 1.6 to $2.8 \%$ of this population have cow milk allergy (Poms et al., 2004). About $85 \%$ of those children outgrow their milk allergy after the age of three years. Approximately 0.3 to $7.5 \%$ of the world population is reported to be affected by cow milk allergy (El-Agamy, 2007).

Almost all proteins in milk are allergens even at low concentrations (Wal, 2004). Milk contains two types of protein, casein and whey in 80:20 ratio. $\alpha$-lactalbumin and $\beta$-lactoglobulin are the major components of whey. Caseins are the most allergenic proteins in milk followed by $\beta$-lactoglobulin and $\alpha$-lactalbumin (Natale et al., 2004). Milk is a very rich nutrition source and is used as an ingredient in most of the weaning foods. Hence avoiding milk may lead to malnutrition in children and may affect their growth. Several researchers attempted to reduce milk allergenicity by applying different processing treatments. Although some of the treatments reduced allergenicity to some extent, deterioration in the quality of milk was observed.

Heat denaturation changes the conformation of proteins and thus reduces the antigenicity of the protein (Mondoulet et al., 2005). However, heat treatment may lead to the loss of nutritional quality of the product. Enzymatic treatment can reduce the allergenicity by hydrolyzing milk proteins, but development of bitterness and off-flavor in hydrolyzed milk makes it unacceptable for children (El-Agamy, 2007). A nonthermal technology is needed to reduce the allergenicity of milk proteins without damaging its nutritional quality.

Byun et al. (2002) conducted a study to estimate the effect of gamma irradiation in reducing food allergy. Gamma irradiation treatment was shown to have reduced the allergenicity of different allergenic foods by structurally altering the epitope regions responsible for IgE binding. A study on ionizing radiation treatment indicated that it could change the antigenicity of food allergens by eliminating or modifying IgE binding epitopes (Lee et al., 2001).

UV-C has been used as a bactericidal agent since 1928 (Xenon, 2003). UV light can be used as a nonthermal treatment to kill pathogenic bacteria without adversely changing the quality of food (Smith et al., 2002). A recent study on pulsed UV light treatment of peanut and cow milk proteins resulted in reduced allergenicity. Previous literature suggests the photothermal, photophysical and photochemical effects of PUV light on food systems might result in the formation of aggregates and protein insolubility caused by the treatment (Chung et al., 2008; Anugu, 2009).

Nonthermal atmospheric plasma (NTAP) treatments are shown to have germicidal effect on food pathogens, requiring less energy and time compared to other techniques (Akitsu, 2005). NTAP operates at ambient temperatures which allow for sterilization of heat labile instruments and low temperature food processing. Absence of toxic by-products by plasma afterglow reduces the hazards of exposure to operators and consumers. The plasma glow consists of UV radiation, excited atoms, molecules and free radical components that are perceived to be responsible for germicidal effect (Laroussi, 2005). Recent developments on using NTAP to reduce allergenicity of shrimp and wheat protein extracts (Nooji, 2011; Shriver, 2011) may indicate a potential application of NTAP to reduce the allergenicity of milk proteins.

Ultrasound in combination with other treatments like heat can be used as an alternative processing treatment for preservation of liquid food products (Lee et al., 2009). The effect of ultrasound treatment on harmful bacteria was first reported in 1920's (Harvey et al., 1929). The effect of ultrasound treatment on bacteria is attributed to cavitation phenomenon. Cavitation is 
the formation of bubbles or cavities in liquids and the collapse of these bubbles releases intense shock waves that can cause considerable damage to surrounding material (Lee et al., 2009). High-intensity ultrasound is successfully used as an efficient food processing technology in dairy industry for homogenizing emulsions, deactivating enzymes, enhancing extraction processes and accelerating dehydration, ageing and ripening processes (Villamiel et al., 2000). A recent study on the effect of high intensity ultrasound on shrimp extract showed a significant decrease in the allergenicity, which was confirmed by ELISA and immunoblot analysis (Li et al., 2005).

Based on previous literature, nonthermal food processing techniques such as high intensity ultrasound, UV-C and atmospheric plasma treatments are candidates to reduce the allergenicity of milk proteins and potentially produce a hypoallergenic milk product. The objective of this study was to test the efficacy of UV-C, nonthermal plasma and high intensity ultrasound treatments in reducing the allergenicity of major milk proteins, namely $\alpha$-casein, $\beta$ lactoglobulin and $\alpha$-lactalbumin.

\subsection{Materials and methods}

\subsection{Experimental Design}

Each nonthermal method of UV-C, NTP and high intensity ultrasound with each combination of $\alpha$-casein and whey protein was considered a separate experiment. Each experiment consisted of four exposure times including a control of zero exposure time and each experiment was replicated three times. Each experiment was analyzed with a one-way analysis of variance (ANOVA) $(\alpha=0.05)$ to determine any significant differences among the exposure times. When significant differences existed, the Tukey's test was used to determine differences among the exposure times when the ANOVA resulted in significance. SAS 9.2 (SAS Institute Inc., Cary, NC) software was used for the analysis.

\subsection{Materials}

2.2.1 Milk Protein: Milk proteins were purchased from Sigma Chemical Co. (St Louis MO). Isolated alpha casein (lyophilized powder, chromatographically purified, approximately $70 \mathrm{~g} / 100 \mathrm{~g}$ by electrophoresis, catalog number: C6780) and whey powder (protein concentration>11 g/100g, catalog number: W1500) were used.

2.2.2 Reagents for SDS-PAGE: Tris/Glycine/SDS running buffer (Catalog number: 161-0732) containing $24 \mathrm{mmol} / \mathrm{L}$ Tris, $192 \mathrm{mmol} / \mathrm{L}$ glycine and 0.1 $\mathrm{g} / 100 \mathrm{ml} \mathrm{SDS}, \mathrm{pH} 8.3$ was obtained from Bio-Rad Laboratories (Hercules, CA). Laemmli sample buffer (Catalog number: 161-0737), 2Mercaptoethanol (catalog number: 161-0710) reagent and Coomassie Brilliant Blue R-250 stain (Catalogue number 161-0435) were purchased from Bio-Rad laboratories. Mini-PROTEAN TGX precast gels of 4-20\% (catalog number: 456-1096) were purchased from Bio-Rad laboratories. Mark 12 unstained standard molecular weight marker (catalog number: LC5677) was purchased from Invitrogen life technologies (Grand Island, NY).

2.2.3 Reagents and materials for Ci-ELISA: A pool of human sera of three patients with documented history of milk allergy was used. It was obtained from Plasma Lab International, Everette, WA. Secondary antibody MSE ANTI-HMN IGE (FC)-HRP (catalog number: 9250-05) was purchased from SouthernBiotech (Birmingham, Alabama). Costar 96-Well EIA/RIA plates (catalog number: 07-200-642) were purchased from Fisher Scientific (Pittsburgh, PA).

\subsection{Methods}

2.3.1. Preparation of protein samples: $\alpha$-casein was dissolved in sodium phosphate buffered saline (PBS) solution prepared freshly with $\mathrm{NaCl}$ of $0.15 \mathrm{~mol} / \mathrm{L}$ having $\mathrm{pH}$ of 7.4 and molarity of 
$0.01 \mathrm{~mol} / \mathrm{L}$. The final concentration of $\alpha$-casein solution was adjusted to $2.0 \mathrm{mg} / \mathrm{ml}$. Whey powder was also dissolved in the same buffer and adjusted to concentration of $40 \mathrm{mg} / \mathrm{ml}$ so that minimum of $2 \mathrm{mg} / \mathrm{ml}$ concentration each of $\beta$-lactoglobulin and $\alpha$-lactalbumin were present in samples to represent approximate concentration of casein in cow milk.

2.3.2 UV-C treatment: A UV tunnel custom built by the DDK Scientific Corporation (Belleville, IL) was used in this study. The tunnel housing was made of a polished aluminum to maximize the amount of ultraviolet reflection from its $8 \mathrm{UV}-\mathrm{C}$ lamps. The UV-C lamp specifications were: $60.9 \mathrm{~cm}$ length, $50.5 \mathrm{~cm}$ arc length, $8.7 \mathrm{UV}-\mathrm{C}$ watts and a wavelength of $253.7 \mathrm{~nm}$. Based on previous calculations by Carpenter (2009) the energy available for the samples were 53, 100.7, 150.9, 201.2 and $252 \mathrm{~mJ} / \mathrm{cm}^{2}$ after $15,30,45,60$ and 75 seconds, respectively.

Five $\mathrm{ml}$ of protein sample was taken in a glass petri dish (100 mm diameter and $15 \mathrm{~mm}$ height) to fill a depth of approximately $1 \mathrm{~mm}$. The maximum treatment time was set at $15 \mathrm{~min}$, based on a preliminary test to avoid extensive sample evaporation. Sample petri dish was placed in the tunnel and was exposed to UV-C light for a set period of time. After the treatment, the samples were stored at frozen temperature $\left(-20^{\circ} \mathrm{C}\right)$ in $50 \mathrm{ml}$ centrifuge tubes before analysis with SDS-PAGE and ELISA.

2.3.3 High intensity ultrasound treatment: A high intensity ultrasound liquid processor (Sonics Vibracell VC 505) (Newtown, CT) was used for this study. It operates at a net power output of 500 Watts and $20 \mathrm{kHz}$ frequency. The probe was constructed of a titanium alloy with a $13 \mathrm{~mm}$ tip diameter. Fifteen $\mathrm{ml}$ of sample was taken in a $20 \mathrm{ml}$ beaker. The sample beaker was placed under the sonicator probe for a set period of time. After the treatment, the samples were frozen $\left(-20^{\circ} \mathrm{C}\right)$ and then analyzed with SDS-PAGE and ELISA. The maximum treatment time of $30 \mathrm{~min}$ in this study was decided by maximum sonication time permissible for the equipment. After observing no noticeable changes in band intensities in SDS-PAGE of the samples treated in room temperature during a preliminary test, it was decided to preheat samples to $60{ }^{\circ} \mathrm{C}$ for this study.

2.3.4 NTAP treatment: The NTAP equipment consisted of an argon gas cylinder, a plasma electrode unit consisting of an inner cylindrical electrode surrounded by a tubular outer electrode, and RF power supply. Argon gas was delivered at a rate of $30.7 \mathrm{l} / \mathrm{min}$ to the electrode unit. An RF-10 radio frequency (RF) power supply (RF Plasma Products, Marlton, NJ) generated a $13.56 \mathrm{MHz}$ RF signal which was transmitted to the electrode through a $50 \mathrm{ohm}$ cable. An indicator displayed the forward and reflected power. The actual load impedance of the circuit was achieved by conversion of the RF output via a Model MN 1000 impedance matching network (RF Plasma Products, Marlton, NJ). The quartz tube between the inner and outer electrodes was enclosed by a helical cooling tube which supplied tap water to cool the electrode tip. The argon gas flowed through the discharge gap and plasma afterglow was produced as a result of the ionization of the gas and resulting reactive species that were then propelled from the end of the electrodes at high velocity.

Five $\mathrm{ml}$ of sample was taken in a Teflon petri plate. Sample petri plate was placed under plasma afterglow for a set period of time. The treated samples were then frozen $\left(-20^{\circ} \mathrm{C}\right)$ before analysis with SDS-PAGE and ELISA. The maximum treatment time was set at $15 \mathrm{~min}$, based on a preliminary test to avoid extensive sample evaporation.

2.3.5 SDS-PAGE: Electrophoresis gel equipment (XCell SureLock® Mini-Cell, Life Technologies, Carlsbad, CA) was used to conduct all SDS PAGE analysis with pre-cast gels by Bio-rad (Hercules, CA). The equipment consists of a gel chamber and a power supply controller. SDS-PAGE was used to compare and contrast the differences in the intensities of protein bands 
for control and treated samples. The gel was placed in a gel chamber and a $1 \mathrm{~g} / 100 \mathrm{ml}$ SDS buffer was added. A $50 \mu 1$ sample was added to $50 \mu 1$ of SDS-solution in a centrifuge tube. These samples were heated in a hot water bath at $95^{\circ} \mathrm{C}$ for 5 min to unfold their protein structure and then spun in a centrifuge for 5 seconds at $1,677 \times \mathrm{g}$. Five $\mu 1$ of the resultant solution was then loaded into gel. Different wells in the gel were loaded with samples, controls and molecular weight marker. The gel chamber was closed tightly with the lid to run the gel for $45 \mathrm{~min}$.

Gel was removed from gel plate after taking it out from electrophoresis equipment. The gel was rinsed for three times in deionized water and Coomassie staining solution was added and shaken for overnight. Destaining of the gel was done using multiple washes of ultrapure water over a period of approximately 24 hours. Gel picture was taken for visible analysis.

2.3.6. Ci-ELISA: A Synergy Mx Monochromator-Based Multi-Mode Micro plate reader, by BioTek Instruments Inc., (Winooski, VT) was used to quantify the change in IgE binding by ELISA. A sample plate was inserted in the reader and the computer connected to the reader preloaded with software gave absorbance readings of each well at $490 \mathrm{~nm}$. Ci-ELISA was conducted to quantify the allergens present in the treated sample using the protocol described by Lee et al. (2001). Sodium bicarbonate of $0.84 \mathrm{~g}$ was added to $80 \mathrm{ml}$ of water and $\mathrm{pH}$ was adjusted to 9.6 and made up to $100 \mu \mathrm{L}$.

A $100 \mu \mathrm{L}$ of diluted desired sample was mixed with $10 \mathrm{ml}$ of $0.1 \mathrm{~mol} / \mathrm{L}$ sodium bicarbonate buffer ( $\mathrm{pH}$ 9.6) and $100 \mu \mathrm{l}$ of this solution was applied on a well of ELISA plate. The plate was then incubated overnight at $4^{\circ} \mathrm{C}$ to attach proteins to wells in ELISA plate. The solutions were then discarded and wells were washed with PBST solution for three times and plates were patted each time on a mat to drain remaining droplets in wells. Blocking solution was prepared by adding gelatin at $1 \mathrm{~g} / 100 \mathrm{ml}$ of de ionized water. One hundred $\mu \mathrm{L}$ of the blocking solution was applied to each well and incubated for $1.5 \mathrm{~h}$ for blocking further binding of protein in wells. Plates were washed again with PBST solution for three times. After washing, $50 \mu 1$ of different diluents of sample solution serially diluted (1000, 100, 10, 1 and $0.1 \mu \mathrm{g} / 50 \mu \mathrm{l})$ in PBS were added. The patient's sera was diluted to 50 times with PBS and added to each well in a quantity of $50 \mu \mathrm{l}$. This was incubated for two hour followed by washing for three times with PBST solution. One hundred $\mu 1$ of secondary antibody (1:3000 with PBS) was added to each well and incubated for one hour. The plates were then washed for three times using PBST. Substrate was prepared by adding five $\mathrm{mg}$ O- Phenylenediamine dihydro Chloride (OPD) in ten $\mathrm{ml}$ of citrate phosphate, $\mathrm{pH} 5$ and $3.4 \mu \mathrm{L}$ of $30 \mathrm{ml} / 100 \mathrm{ml}$ hydrogen peroxide. One hundred $\mu \mathrm{L}$ of this substrate was added for color reaction for $20 \mathrm{~min}$ before stopping it with $50 \mu 1$ of $2.0 \mathrm{~mol} / \mathrm{L}$ $\mathrm{H}_{2} \mathrm{SO}_{4}$. The color change was observed from clear to golden yellow. The absorbance was measured at $490 \mathrm{~nm}$ by a Synergy Mx Monochromator-Based Multi-Mode Micro plate reader, (Bio-Tek Instruments Inc., Winooski, VT). The absorbance readings were used for further allergen analysis.

Absorbance $\left(\mathrm{A}_{1000}, \mathrm{~A}_{100}, \mathrm{~A}_{10}, \mathrm{~A}_{1}\right.$ and $\left.\mathrm{A}_{0.1}\right)$ values were collected at each concentration $(1000,100,10,1$ and $0.1 \mu \mathrm{g} / 50 \mu \mathrm{l})$. Percentage binding capacity of the proteins attached to the plate was calculated by dividing the absorbance values at each concentration (for example, $\mathrm{A}_{1000}$ ) with the absorbance at the lowest concentration $\left(\mathrm{A}_{0.1}\right)$. The percentage binding of the protein at $1000 \mu \mathrm{g} / 50 \mu \mathrm{l}$ concentration was calculated as $\left(\mathrm{A}_{1000} / \mathrm{A}_{0.1}\right) \times 100$. A graph was plotted with percentage binding values $(5$ concentrations $=5$ data points $=$ one line $)$ for each treatment time . Slope for each line was calculated, and the percentage change in slope was calculated, to indicate percentage reduction in allergenicity.

\subsection{Results and Discussion}




\subsection{UV-C treatment}

UV-C treatment was observed to reduce the liquid volume of protein solution. The volume of treated solution decreased with increase in treatment time. This moisture loss was due to increase in temperature (up to $15^{\circ} \mathrm{C}$ ) and high area of exposure of UV-C which led to evaporation of water molecules. After 15 min of treatment, up to $40 \%$ of the sample was evaporated. Approximately $3.1 \mathrm{ml}$ was collected after $15 \mathrm{~min}$ of UV-C treatment from $5 \mathrm{ml}$ of initial sample.

3.1.1 SDS PAGE for $\alpha$-casein treated with UV-C: UV-C treated samples were analyzed using SDS-PAGE for their electrophoretic profiles. Figure 1 shows SDS-PAGE profile of $\alpha$-casein control and UV-C treated samples. The samples were treated for 5, 10 and $15 \mathrm{~min}$. The $\alpha$-casein band is located at approximately $35 \mathrm{kDa}$ for the control sample. Decrease in intensity of this band was observed with treatment time indicating reduced concentration of protein and hence less amount of allergen present in the treated sample.

These results were comparable with the work of Lee et al. (2001, 2005), where gamma irradiation was used to reduce $\alpha$-casein and soy proteins at the dosage levels of 3, 5, and $10 \mathrm{kGy}$. Band intensities of the soy proteins were reduced with $\gamma$-irradiation and were perceived to be due to slight breakdown of polypeptide chains. A recent study reported that pulsed UV (PUV) light treatment was effective in completely removing the bands of $\alpha$-casein after 180 s of treatment (Anugu, 2009). Kolakowska (2003) stated that UV light forms super radicals which can further induce carbohydrate linkage, protein cross linking and fragmentation. Lee et al. (2005) observed cross linked products of degraded proteins that could not penetrate through running gel after treatment with high energy doses of gamma irradiation. Higher weight aggregates can be generated with the formation of disulfide bonds, hydrophobic and electrostatic interactions and inter protein cross linking (Davies et al., 1987).

3.1.2 Ci-ELISA for $\boldsymbol{\alpha}$-casein treated with UV-C: Ci-ELISA was used to quantify the change in the IgE antibody binding of $\alpha$-casein treated with UV-C. A pool of plasma serum obtained from three individuals who were sensitive to milk proteins was used for this analysis. The concentrations of protein used for the analysis where 1000, 100, 10,1 and $0.1 \mu \mathrm{g} / 50 \mu \mathrm{L}$. Figure 2 shows percent IgE binding capacity of proteins attached to ELISA wells containing UV-C treated and untreated (control) samples. One-way ANOVA was used to determine a significant difference $(p<0.05)$ existed among the percent binding capacity of the treatment times.

In Figure 2, higher values of \% IgE binding on y-axis indicates decreased IgE binding to proteins in sample solutions. Reduction of binding capacity of the IgE antibody to the protein in sample solution is indicated by increase in slope of lines. Lee et al (2001) observed change in the slope of the curve indicating conformation alteration of epitope, induced by gamma irradiation. The slopes of lines increased with increase in treatment time indicating the reduction in binding capacity of UV-C treated $\alpha$-casein samples. The percentage change in the slope of 15 min line in the graph was $25 \%$. Hence based on percentage change in slope, reduction of IgE binding capacity after 15 min treatment may be expressed as 25\% (Table1). It can be observed from Table 1 that longer treatment time leads to increased reduction in allergenicity. Tukey's test indicated that treatment times of 10 and $15 \mathrm{~min}$ were significantly different in binding capacity from control (no treatment) and 5 min (Table1).

Similar pattern of results were observed in a recent study on PUV light treatment on $\alpha$ casein (Anugu, 2009), where the allergenicity was reported to decrease with increase in treatment time. Lee et al. (2001) suggested that the change in the conformational epitope structures of proteins were responsible for reduction in allergenicity with gamma irradiaton. UV- 
$\mathrm{C}$ was also expected to have similar effect on proteins. Casein is a very heat stable protien and can withstand upto $130^{\circ} \mathrm{C}$ temperature for one hour (Lee, 1992). This indicates that the increase in tempearture in the UV tunnel may not be the factor effecting the change in allergenicity.

According to Carpenter (2009) the approximate UV-C energy available in the UV tunnel after $15 \mathrm{~min}$ of exposure was $3500 \mathrm{~mJ} / \mathrm{cm}^{2}$ which was less than the maximum energy provided by PUV light system $\left(199.8 \mathrm{~J} / \mathrm{cm}^{2}\right.$ at $9.6 \mathrm{~cm}$ distance and $180 \mathrm{~s}$ treatment) used for milk in recent studies (Krishnamurthy, 2006). However several factors contribute to the actual amount of energy absorbed by the sample such as the transparency, optical properties and presence of solids in the sample. Milk is a translucent liquid and the actual energy absorbed by milk is expected to be significantly less than protein solutions used in this study.

As shown in the Table1, based on the \% change in slope, UV-C treatment at 15 min was effective in reducing the IgE binding capacity of $\alpha$-casein by $25 \%$. This treatment was less effective compared to PUV light treatment (Anugu, 2009) and can be attributed to the lower energy provided by the UV tunnel in comparison of PUV system. Further studies with higher UV-C doses might yield better results.

3.1.3 SDS-PAGE for whey treated with UV-C: Figure 3 shows the SDS-PAGE gel pictures of UV-C treated and control whey samples. Significant moisture loss (40\%) was also observed in whey solutions after $15 \mathrm{~min}$ of treatment. The bands of $\alpha$-lactalbumin and $\beta$-lactoglobulin can be observed at 14 and $18 \mathrm{kDa}$ respectively. The band intensities of these proteins were reduced with increase in treatment time whereas the bands of other proteins like bovine serum albumin (BSA), lactoferrin and Immunoglobulins were completely removed (bands observed at approx $66.3 \mathrm{kDa}$ for BSA, $80 \mathrm{kDa}$ for Lactoferrin and $150 \mathrm{kDa}$ for Immunoglobulins) after $15 \mathrm{~min}$ of treatment. Depending on the amino acid composition and molecular structure, proteins may exhibit different responses to treatment (Gennadios et al, 1998).

Gamma irradiation treatment of BSA and $\beta$-lactoglobulin were reported to result in disruption of ordered structure, degradation, cross linking and aggregation of polypeptide chain (Cho et al., 2000). Chung et al., (2008) reported that the PUV light treatment resulted in coagulation of peanut proteins and formation of insoluble precipitates resulting lesser availability for IgE binding. A recent study on PUV light treatment of whey protein solution resulted in complete removal of bands of both $\beta$-lactoglobulin and $\alpha$-lactalbumin after $180 \mathrm{~s}$ treatment (Anugu, 2009). This may be because of the higher energy delivered by the PUV treatment than the UV-C treatment used in this study.

3.1.4 Ci-ELISA for whey protein treated with UV-C: The IgE binding capacity of whey solution treated with UV light for 5, 10 and 15 min is shown in Figure 4. One-way ANOVA was used to determine a significant difference $(\mathrm{p}<0.05)$ existed among the binding capacities of the samples.

Anugu (2009) stated that 7.4 fold reduction of the allergenicity of whey was observed after $150 \mathrm{~s}$ of treatment with PUV at $9.6 \mathrm{~cm}$ distance from lamp. Using gamma irradiation, Lee et al. (2001) successfully reduced the allergenicity of $\beta$-lactoglobulin by 7 fold. A change in slope of the curve of IgE binding capacity for each treatment condition was observed in this study. Steeper slopes of curve indicate higher reduction in allergenicity (Figure 4). The slopes of the UV-C treated whey solutions increased with increase in treatment time indicating reduction in binding capacity. The percentage change in slope of 15 min line represents the percent reduction of allergenicity as $27.7 \%$ (Table2). Hence longer treatment time led to increased reduction in allergenicity. Tukey's test shows that the binding capacity at treatment times 5, 10 and 15 min were significantly different from each other and control (no treatment) (Table2). 
Based on the change in slope of the lines of different treatment times, UV-C light treatment was effective in reducing the allergenicity of whey by $27.7 \%$. PUV light treatment of whey solution was more effective in reducing the allergenicity (Anugu, 2009) which can be attributed to the higher energy and pulse factor. Higher intensity UV-C might yield better results. At the treatment conditions used in this study, the UV -C has the potential to kill harmful bacteria in the sample (Carpenter, 2009). The design of UV-C treatment conditions may be improved to reduce the allergenicity of major milk allergens so that the same UV tunnel can be used to simultaneously reduce allergenicity and kill pathogens.

\subsection{High intensity ultrasound treatment}

SDS PAGE gel pictures of $\alpha$-casein and whey solutions (Figures 5 and 6) treated with high intensity ultrasound show no visible change in the band intensities of all three proteins. Ci-ELISA of both $\alpha$-casein and whey solutions revealed no significant difference $(p>$ 0.05 ) among the binding capacity of samples and controls for both $\alpha$-casein and whey protein.

High intensity ultrasound treatment was not effective in reducing the allergenicity of major milk proteins at the given treatment conditions ( $500 \mathrm{~W}$ power and $20 \mathrm{kHz}$ frequency). $\mathrm{Li}$ et al. (2005) stated that high intensity ultrasound treatment was effective in reducing the allergenicity of shrimp after $180 \mathrm{~min}$ of treatment at $30 \mathrm{~Hz}$ frequency and $800 \mathrm{~W}$ power. Higher intensities and longer treatment time might yield better results with high intensity ultrasound treatment.

\subsection{Nonthermal atmospheric plasma treatment}

SDS PAGE gel pictures of $\alpha$-casein and whey solutions (Figures 7 and 8) show no visible change in the band intensities of all three proteins treated with nonthermal atmospheric plasma.

Ci-ELISA of both $\alpha$-casein and whey solutions revealed no significant difference $(p>$ $0.05)$ in IgE binding of treated protein from that of controls. At the treatment conditions used, nonthermal plasma treatment was not effective in reducing the allergenicity of major milk protiens. Previous literature on the effect of nonthermal plasma treatment on shrimp and wheat allergens (Shriver 2011, Nooji 2011) indicated that this treatment was effective in reducing the allergenicity of these proteins. These authors used nonthermal plasma equipment with voltage of $30 \mathrm{kV}$ and a frequency of $60 \mathrm{~Hz}$. Also, the samples were directly exposed to plasma in both the studies (Shriver 2011, Nooji 2011). The power level of NTAP equipment used in our lab was 60 $\mathrm{W}$. And the samples were exposed to the plasma afterglow (indirect plasma). Hence higher plasma power and direct exposure of sample to plasma might yield better results towards reducing the allergenicity of major milk allergens.

\subsection{Conclusions}

UV-C treatment was shown to have reduced the allergenicity of milk proteins by 25 to $27.7 \%$ after 15 min of treatment. Although the trend indicated that UV-C can alter the allergenicity of milk proteins this reduction was not enough for safe consumption. Higher UV-C intensity may be required to obtain hypoallergenic milk products. The tested conditions of high intensity ultrasound and nonthermal atmospheric plasma treatments did not reduce the allergenicity of $\alpha$-casein and whey proteins. Higher intensities and longer treatment times might yield better results with high intensity ultrasound treatment. Applying direct plasma instead of afterglow might yield better results that are comparable to the application of plasma treatment in literature. 


\section{Acknowledgement}

This project was supported by the Department of Plant, Soil and Agricultural Systems, College of Agricultural Sciences, and the Office of Vice Chancellor for Research, Southern Illinois University, Carbondale, IL. Dr. Punit Kohli provided the high intensity ulstrasound equipment used in the analysis. Justin Hennings provided valuable assistance in SDS-PAGE analysis. Dr. John Haddock provided the nonthermal plasma equipment used in the research. Drs. Ahmad Fakhoury, Ali Srour and Nawneet Kurrey provided kind help on ELISA analysis. Mr. Daniel Atherton provided great assistance with statistical analysis.

\section{References:}

Akitsu T., Ohkawa H., Tsuji M., Kimura H., Kogoma M. (2005). Plasma sterilization using glow discharge at atmospheric pressure. Surface and Coating Technology. 193, 29-34.

Anugu Akshay Kumar. (2009). Effect of pulsed UV lights and pulsed electric fields on selected isolated milk proteins and their allergenic properties. Master's thesis. Alabama A \& M University.

Byun M. W., Lee J. W., Yook H. S., Jo C. R., Kim H. Y. (2002). Application of gamma irradiation for inhibition of food allergy. Radiaiont Physics and Chemistry. 63(3-6), 369-370.

Carpenter Chrstopher E. (2009). Impact of ultraviolet energy on Strawberry shelf life. Master's thesis. Southern Illinois University, Carbondale.

Cho Y., Song K. B. (2000). Effect of $\gamma$-irradiation on the molecular properties of BSA and $\beta$ lactglobulin. Journal of Biochemistry Molecular Biology. 33, 133-137.

Chung S. Y., Yang W., Krishnamurthy K. (2008). Effects of Pulsed UV light on Peanut Allergens in Extracts and Liquid Peanut Butter. Journal of Food Science. 73, 5, 400-404.

Davies K. J. A., Delsignore M. E. (1987). Protein damage and degradation by oxygen radicals III. Modification of secondary structure and tertiary structure. Journal of Biological Chemistry. 262, 9908-9913.

El-Agamy E. I. (2007). The challenge of cow milk protein allergy. Small Ruminant Research. 68, 64-72.

Gennadios A., Rhim J. W., Handa A., Weller C. L., Hanna M. A. (1998). Ultraviolet radiation affects physical and molecular properties of soy protein films. Journal of Food Science63, 2, 225-8.

Harvey E., Loomis A. (1929). The destruction of luminous bacteria by high frequency sound waves. Journal of bacteriology. 17, 314-318.

Krishnamurthy, K. (2006). Decontamination of milk and water by pulsed UV-light and infrared heating. PhD Dissertation, Pennsylvania State University, University Park.

Kolakowska A. (2003). Lipid oxidation in food systems. In Chemical and Functional Properties of Food Lipids, 133-168. Ed. New York, NY: CRC press.

Laroussi M. (2005). Low temperature plasma-based sterilization: overview and state-of-the-art. Plasma Processes and Polymers. 2, 391-400.

Lee Hyoungill, Bin Zhou, Wei Liang, Hao feng, Scott E. Martin. (2009). Inactivation of Escherichia coli cells with sonication, manosonication, thermosonication, and manothermosonication: Microbial responses and kinetics modeling. Journal of Food engineering. 93, 354-364. 
Lee J. W., Kim J. H., Yook H. S., Kang K. O., Lee S. Y., Hwang H. J., Byun M. W. (2001). Effects of gamma radiation on the allergenic and antigenic properties of milk proteins. Journal of Food Protection. 64, 2, 272-276.

Lee M., Lee S., Song K. B. (2005). Effect of $\gamma$-irradiation on the physicochemical properties of soy protein isolate films. Radiation Physics and chemistry. 72, 35-40.

Lee Y. H. (1992). Food-processing approaches to altering allergen. Journal of Pediatrics Supplement. 48-50.

Li Zhenxing, Lin Hong, Cao Limin, Jameel Khalid. (2005). Effect of high intensity ultrasound on the allergenicity of shrimp. Journal Zhejiang University ScienceB. 7, 4, 251-256.

Mondoulet L., Paty E., Drumare M. F., Ah-Leung S., Scheinmann P., Willemot R. M., Wal J. M., Bernard H. (2005). Influence of thermal processing on the allergenicity of peanut proteins. Journal of Agricultural and Food Chemistry. 53, 4547-4553.

Monaci L., Tregoat V., Arjon J., Hengel V., Anklam E. (2006). Milk allergens, their characteristics and their detection in food: A review. European Food Research and Technology. 223, 149179.

Natale M., Bisson C., Monti G., Peltran A., Garoffo L. P., Valentini S., Fabris C., Bertino E., Coscia A., Conti A. (2004). Cow's milk allergens identification by two-dimensional immunoblotting and mass spectrometry. Molecular Nutrition and Food Research. 48, 5, 363369.

Nooji Jyotsna Krishna. (2011). Reduction of wheat allergen potency by pulsed ultraviolet ligh, high hydrostatic pressure and nonthermal plasma. Master's thesis. University of Florida.

Poms R. E., Klein C. L., Anklam E. (2004). Methods for allergen analysis in food: a review. Food Additives and Contaminants. 21, 1, 1-31.

Shriver Kate Sandra. (2011). Effect of selected nonthermal processing methods on the allergen reactivity of Atlantic white shrimp (Litopenaeus Setiferus). Master's thesis, University of Florida.

Smith W. L., Lagunas-Solar M. C., Cullor J. S. (2002). Use of pulsed ultraviolet laser light for the cold pasteurization of bovine milk. Journal of Food Protection. 65, 9, 1480-1482.

Villamiel M, Jong Peter de. (2000). Inactivation of Pseudomonas fluorescens and Streptococcus thermophilus in Trypticase Soy Broth and total bacteria in milk by continuous flow ultrasonic treatment and conventional heating. Journal of food engineering. 45, 3, 171-179.

Wal J. M. (2004). Bovine milk allergenicity. Annals of Allergy Asthma Immunology. 93, 5 S3, 211.

Xenon. (2003). Sterilization and Decontamination using High energy light. Woburn: Xenon corporation. 


\section{Figure Captions}

Figure 1. SDS-PAGE gel picture of UV treated $\alpha$-casein. Lane 1 : Mark 12 MWM; Lane 2: $\alpha$ casein control; Lane 3: $\alpha$-casein UV-C treated (5 min); Lane 4: $\alpha$-casein UV-C treated (10 min); Lane 5: $\alpha$-casein UV-C treated (15 min)

Figure 2. Results of Ci-ELISA showing IgE binding of untreated (control) and UV treated $\alpha$ -

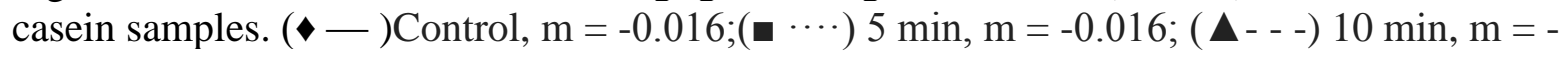
0.013; $(\mathrm{X}-\cdot-\cdot-$ ) $15 \mathrm{~min}, \mathrm{~m}=-0.012$

Figure 3. SDS-PAGE gel picture of UV treated whey protein. Lane 1 : Mark 12 MWM; Lane 2: whey control; Lane 3: whey UV-C treated (5 min); Lane 4: whey UV-C treated (10 min); Lane 5: whey UV-C treated (15 min)

Figure 4. Results of Ci-ELISA showing IgE binding of untreated (control) and UV treated whey

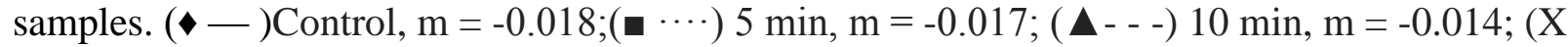
- - — - ) $15 \mathrm{~min}, \mathrm{~m}=-0.013$

Figure 5. SDS-PAGE gel picture of high intensity ultrasound treated whey protein. Lane 1 :

Mark 12 MWM; Lane 2: whey control; Lane 3: whey ultrasound treated (10 min); Lane 4: whey ultrasound treated (20 min); Lane 5: whey ultrasound treated (30 min)

Figure 6. SDS-PAGE gel picture of high intensity ultrasound treated $\alpha$-casein protein. Lane 1: $\alpha$ casein control; Lane 2: $\alpha$-casein ultrasound treated (10 $\mathrm{min})$; Lane 3: $\alpha$-casein ultrasound treated (20 min); Lane 4: $\alpha$-casein ultrasound treated (30 min)

Figure 7. SDS-PAGE gel picture of nonthermal atmospheric plasma treated whey protein. Lane 1: Mark 12 MWM; Lane 2: whey control; Lane 3: whey plasma treated (5min); Lane 4: whey plasma treated (10 min); Lane 5: whey plasma treated (15 min)

Figure 8. SDS-PAGE gel picture of nonthermal plasma treated $\alpha$-casein protein. Lane 1 : Mark 12 MWM; Lane 2: $\alpha$-casein control; Lane 3: $\alpha$-casein plasma treated (5 min); Lane 4: $\alpha$-casein plasma treated (10 min); Lane 5: $\alpha$-casein plasma treated (15 min) 


\section{Figures:}

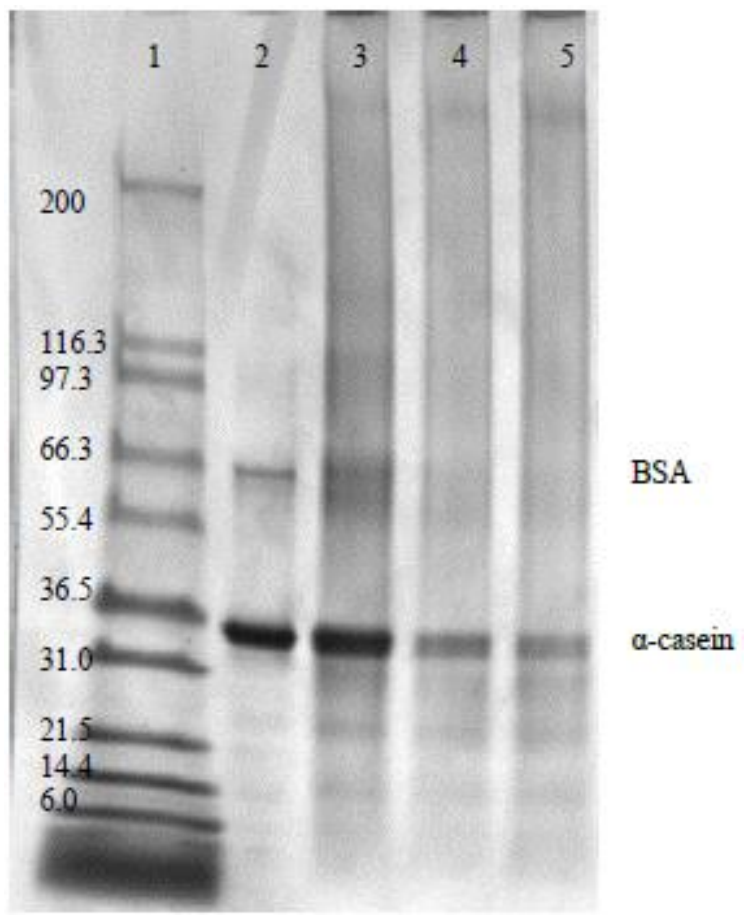

Figure 1. SDS-PAGE gel picture of UV treated $\alpha$-casein. Lane 1 : Mark 12 MWM; Lane 2: $\alpha$ casein control; Lane 3: $\alpha$-casein UV-C treated (5 min); Lane 4: $\alpha$-casein UV-C treated (10 min); Lane 5: $\alpha$-casein UV-C treated (15 min) 


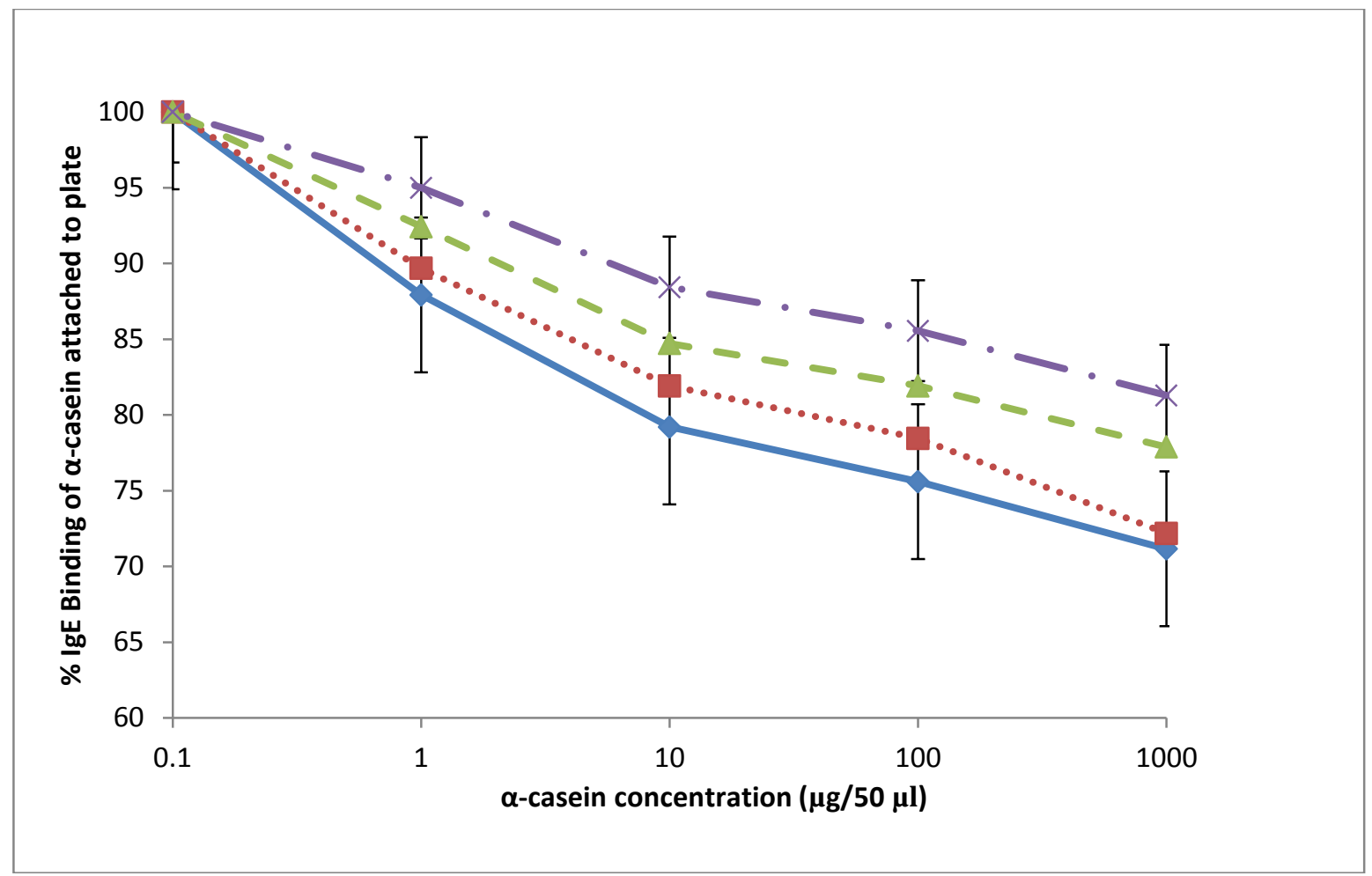

Figure 2. Results of Ci-ELISA showing IgE binding of untreated (control) and UV treated

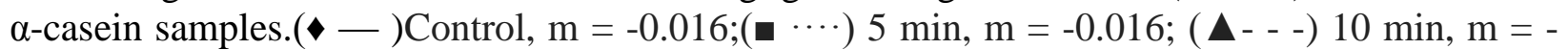
$0.013 ;(\mathrm{X}-\cdot-\cdot-$ - $) 15 \mathrm{~min}, \mathrm{~m}=-0.012$ 


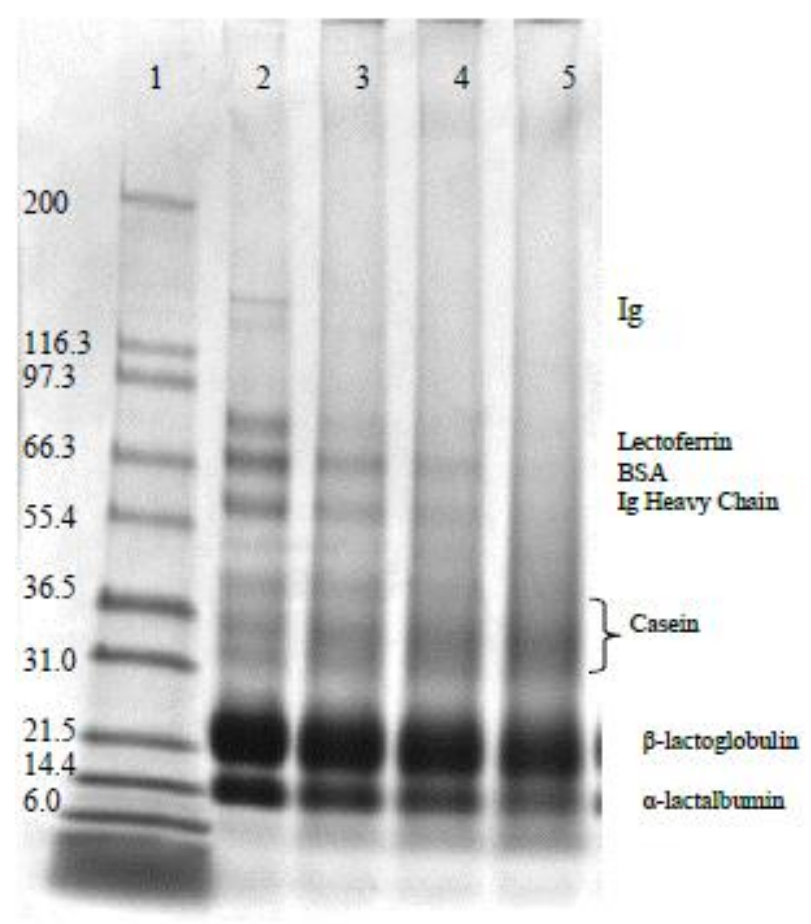

Figure 3. SDS-PAGE gel picture of UV treated whey protein. Lane 1 : Mark $12 \mathrm{MWM}$; Lane 2: whey control; Lane 3: whey UV-C treated (5 min); Lane 4: whey UV-C treated (10 min); Lane 5: whey UV-C treated (15 min) 


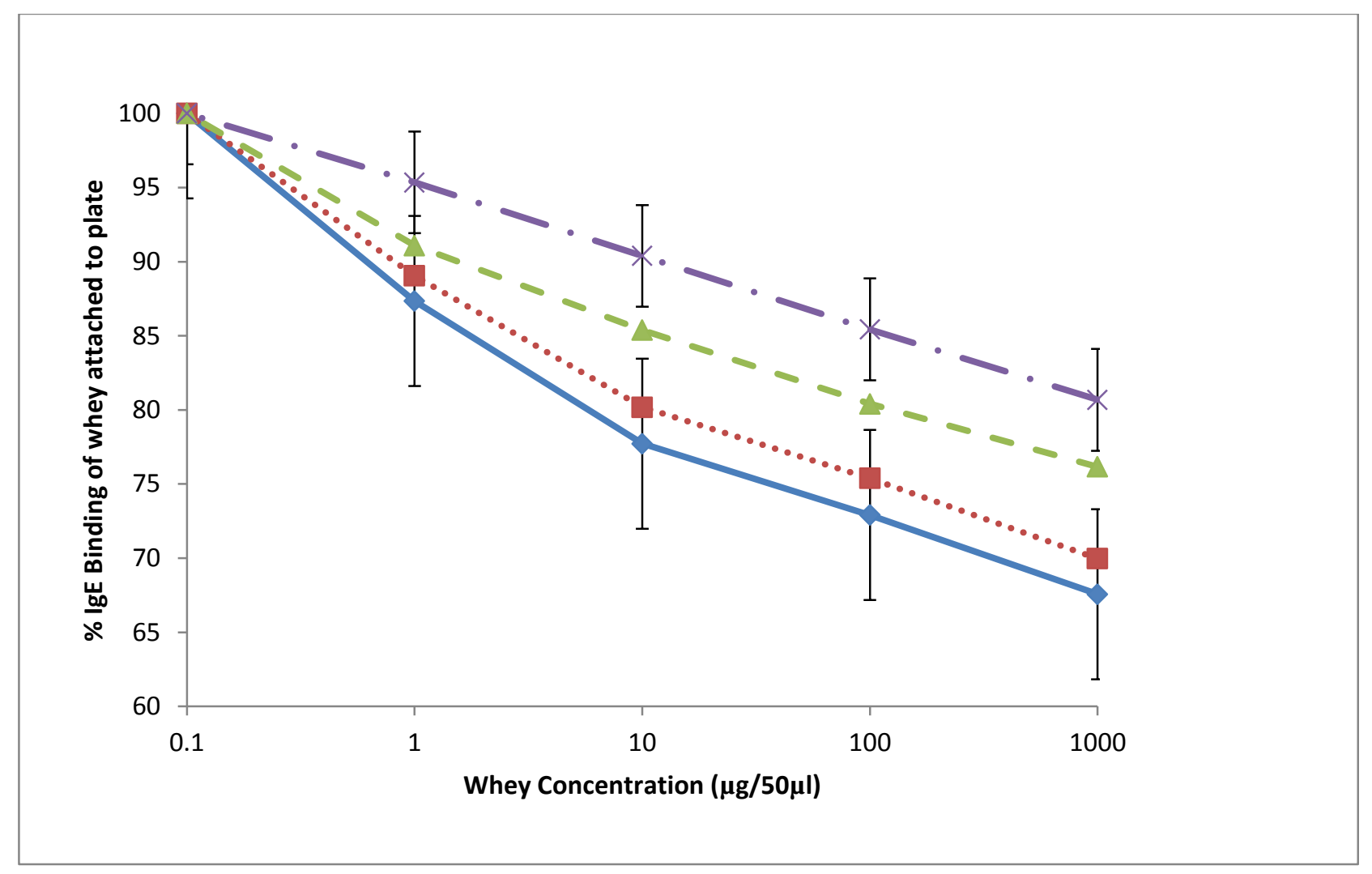

Figure 4. Results of Ci-ELISA showing IgE binding of untreated (control) and UV treated whey

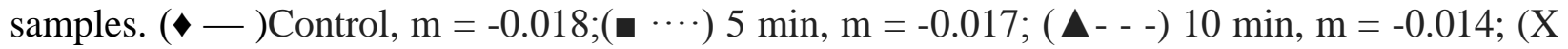
- - _ - ) $15 \mathrm{~min}, \mathrm{~m}=-0.013$ 


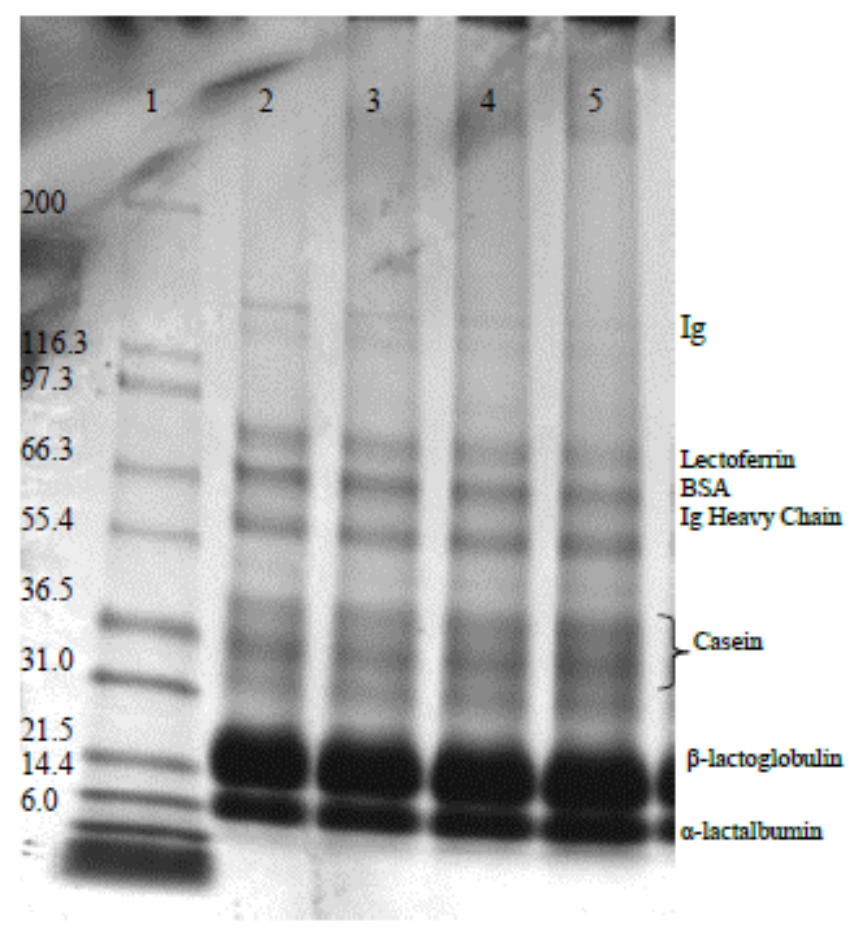

Figure 5. SDS-PAGE gel picture of high intensity ultrasound treated whey protein. Lane 1 : Mark 12 MWM; Lane 2: whey control; Lane 3: whey ultrasound treated (10 min); Lane 4: whey ultrasound treated (20 min); Lane 5: whey ultrasound treated (30 min) 


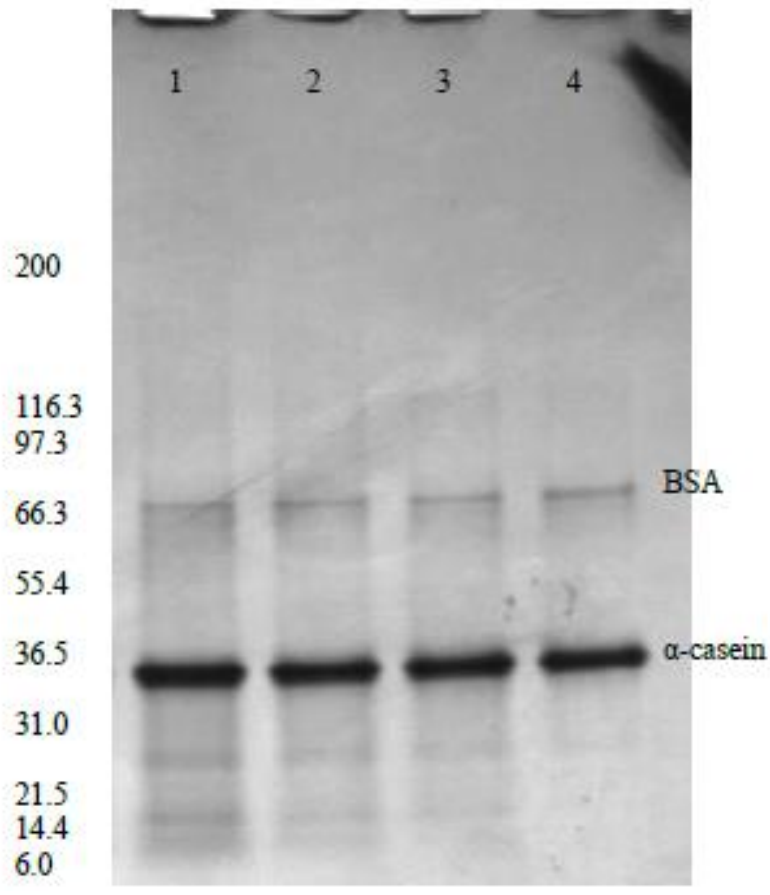

Figure 6. SDS-PAGE gel picture of high intensity ultrasound treated $\alpha$-casein protein. Lane 1: $\alpha$-casein control; Lane 2: $\alpha$-casein ultrasound treated (10 $\mathrm{min})$; Lane 3: $\alpha$-casein ultrasound treated (20 min); Lane 4: $\alpha$-casein ultrasound treated (30 min) 


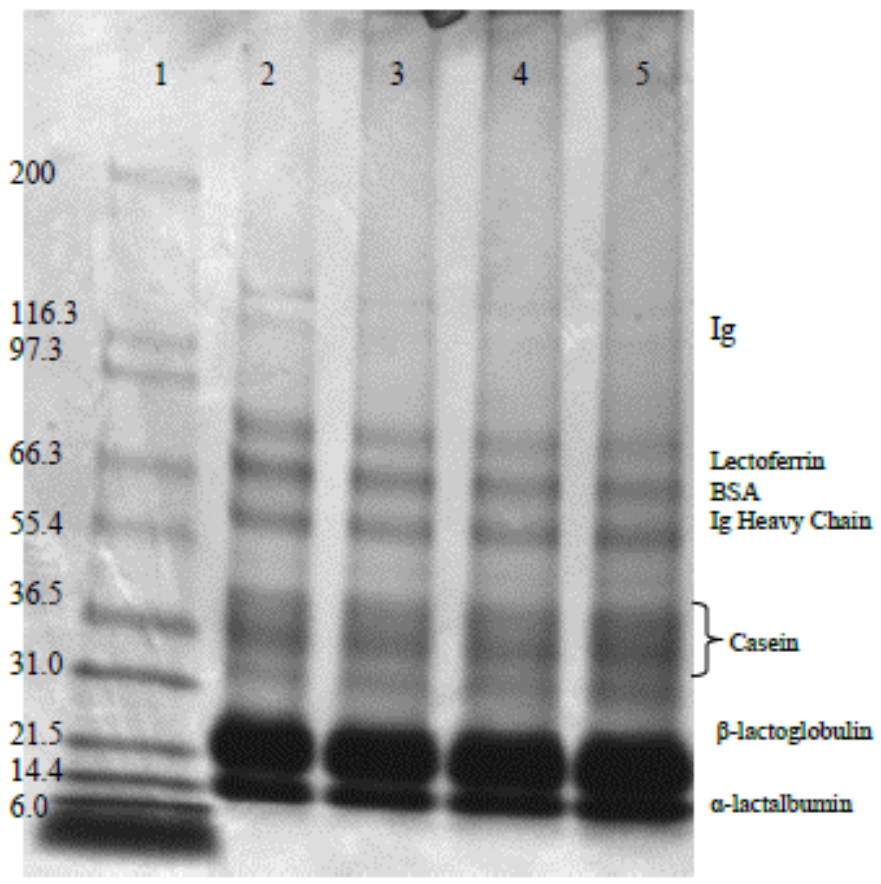

Figure 7. SDS-PAGE gel picture of nonthermal atmospheric plasma treated whe' tein. Lane 1: Mark 12 MWM; Lane 2: whey control; Lane 3: whey plasma treated (5min); Lane 4: whey plasma treated (10 $\mathrm{min})$; Lane 5: whey plasma treated (15 min) 


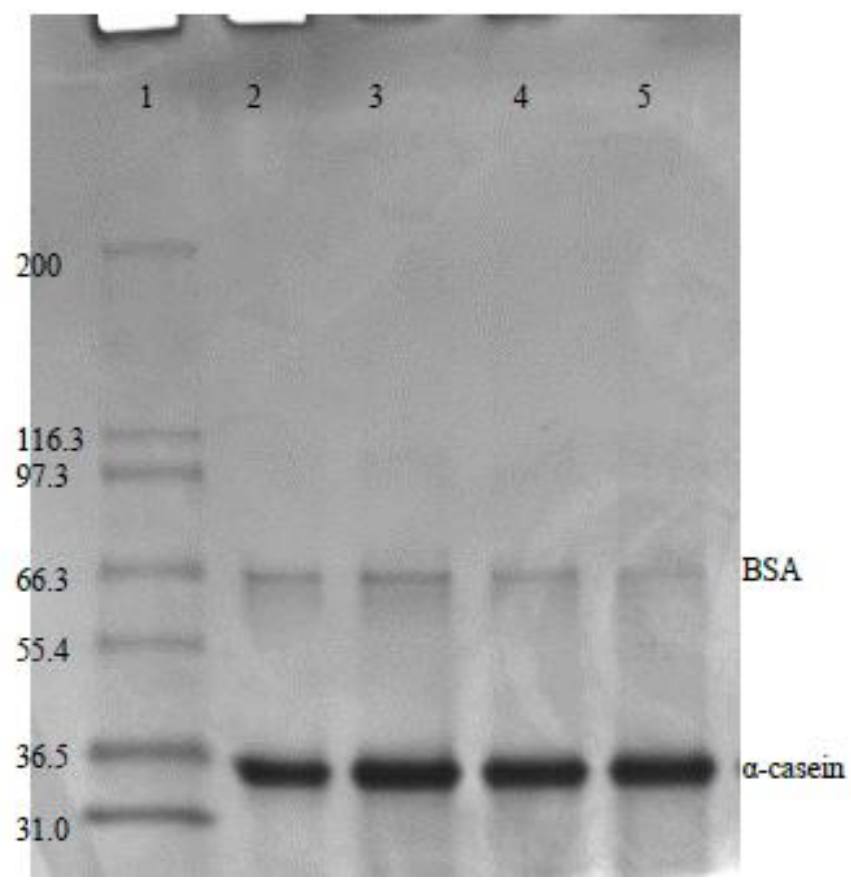

Figure 8. SDS-PAGE gel picture of nonthermal plasma treated $\alpha$-casein protein. Lane 1 : Mark 12 MWM; Lane 2: $\alpha$-casein control; Lane 3: $\alpha$-casein plasma treated (5 min); Lane 4: $\alpha$-casein plasma treated (10 $\mathrm{min})$; Lane 5: $\alpha$-casein plasma treated (15 min) 


\section{Tables:}

Table 1. Ci-ELISA results showing percent binding capacity of a-casein attached to ELISA plate, slopes of lines at different treatment time, and \% change in slope. The \% change in slope indicates percent reduction in allergenicity

\begin{tabular}{llll}
\hline Treatment time & $\begin{array}{l}\% \text { Binding Capacity } \\
\text { at } 1000 \mu \mathrm{g} / 50 \mu \mathrm{L} \\
\text { concentration }\end{array}$ & Slope $(\mathrm{m})$ & \% change in slope \\
& & & \\
\hline Control (no treatment) & $70.10^{\mathrm{a}}$ & -0.016 & 0 \\
\hline 5 min & $71.97^{\mathrm{a}}$ & -0.016 & 18.8 \\
\hline 10 min & $78.19^{\mathrm{b}}$ & -0.013 & 25 \\
\hline 15 min & $81.62^{\mathrm{b}}$ & -0.012 & \\
\hline
\end{tabular}

${ }^{*}$ Values with same superscript letter are not significantly different $(\alpha=0.05)$ 
Table 2. Ci-ELISA results showing percent binding capacity of whey protein attached to ELISA plate, slopes of lines at different treatment time, and \% change in slope. The $\%$ change in slope indicates percent reduction in allergenicity

\begin{tabular}{llll}
\hline Treatment time & \multicolumn{2}{l}{$\%$ Binding capacity at } & Slope $(\mathrm{m})$ \\
& $\begin{array}{l}1000 \mu \mathrm{g} / \mathrm{50} \mu \mathrm{L} \\
\text { concentration }\end{array}$ & & \\
& & & \\
\hline Control (no treatment) & $68.01^{\mathrm{a}}$ & -0.018 & 5.6 \\
\hline 5 min & $70.22^{\mathrm{b}}$ & -0.017 & 22.2 \\
\hline $10 \mathrm{~min}$ & $76.34^{\mathrm{c}}$ & -0.014 & 27.8 \\
\hline 15 min & $81.03^{\mathrm{d}}$ & -0.013 & \\
\hline
\end{tabular}

${ }^{*}$ Values with same superscript letter are not significantly different $(\alpha=0.05)$ 